\title{
Analysis on Deformation Process in Deep Drawing of Sheet Metal Part by FEM
}

\author{
Ramesh Kanttikar ${ }^{1}$, Bharath S Kodli ${ }^{2}$, Ravi B Chikmeti ${ }^{3}$ \\ ${ }^{I}$ M.Tech. (Student), Mechanical Engineering Department, PDA College of Engineering, Gulbarga, Karnataka, \\ India \\ ${ }^{2}$ Professor, Mechanical Engineering Department, PDA College of Engineering Gulbarga, Karnataka, India \\ ${ }^{3}$ Tool \& Die Maker, Govt. Tool Room and Training Centre Bangalore, Karnataka, India
}

\begin{abstract}
Finite element analysis is a simulation technique which evaluates the behavior of components, equipments and structures for various loading conditions. It is a computerized method for predicting how a real object will react to forces by mesh of simpler interlocking structures, the simpler structures or finite elements being agreeable to mathematical analysis. The finite element method is originally developed to study the stresses in complex aircraft structures. Minimization of response times and costs, maximization of the efficiency and quality of product are very important for survival in the competitive manufacturing industry. Sheet metal forming is a widely used and costly manufacturing process, This work will be done to study the finite element (elastic-plastic) analysis of sheet metal forming process using the finite element software. ANSYS simulation is carried out to gain accurate and critical understanding of sheet forming process.
\end{abstract}

Keywords: Metal Forming, Finite Element Analysis, Simulations, LDR

\section{Introduction}

However, while there is a wide use of the finite element method, the simulation of forming processes still provides a great challenge because of the complex physical phenomena to be simulated. In such analyses, for example, large deformations, large strain anisotropic material behavior, contact conditions includmg friction, and fluid-structure interactions need be modeled. These conditions and the frequently complex geometries require fine finite element discretizations and considerable computing resources. Of course, as the available finite element procedures, and available hardware, are being advanced, more complex physical conditions can be modeled accurately[1].The work was carried out to study the finite element (elastic-plastic) analysis of sheet metal forming process using the finite element software. Axisymmetry element mesh and plain strain element mesh were use incorporated with slideline features to model and study the sheet metal forming process [2].

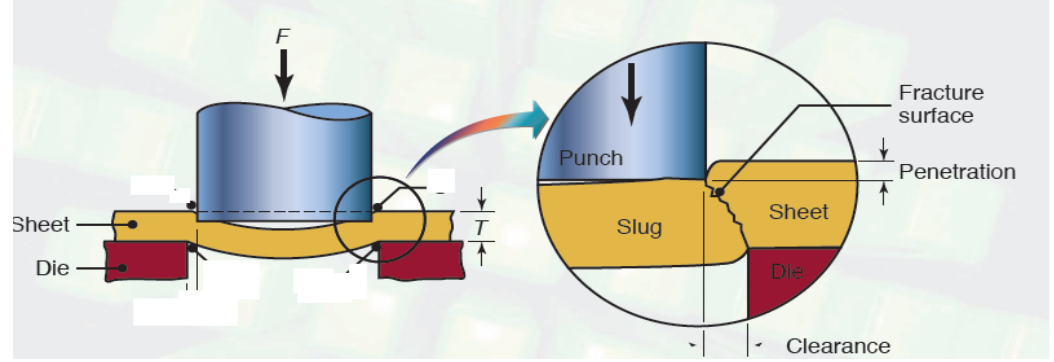

Fig 1: Forming Process

The damage analysis of V-bending dies involved the stress-strain analysis of the forming process using the FEA and applying the damage parameters to the materials data to predict die failure mode and life. The experimental results showed that fracture due to overload and fatigue are the competing die failure modes in Vdie bending [3]. The term simulation is derived from the Latin word "simulare" what means "to pretend". However, the technical meaning of simulation is the description and reproduction of physical and technical processes by use of mathematical and physical models. In comparison with practical tests, the simulation often is cheaper and not so dangerous. Combined with modern methods of computation, the simulation is a powerful tool which gains more and more importance for describing and developing new processing methods. Because of higher requirements on the quality of products and narrow tolerances of measures, optimizing, planning and simulating of forming processes becomes more and more important. As the computational power has increased during the last years, numerical methods play an outstanding roll. The most important numerical method is the method of finite elements (FEM). Numerous finite element programmes have been developed which are able to solve linear, non linear, static, dynamic, elastic, plastic, elastic - plastic, steady state, transient, isothermal as 
well as non isothermal problems [4]. The physical setup of a sheet metal stamping operation consists of three main components: the die, the binder, and the punch. The setup is mounted on a hydraulic or mechanical press with a force rating estimated from the size, material and shape of the desired product. During a stamping operation, the periphery of the sheet metal work-piece is held between the binder and die flange. The contact force between the binder and work-piece is referred to as the binder force. As the punch moves down, the workpiece is pressed into the die, causing plastic deformation in the work-piece material. During the operation the flow of work-piece material into the die is regulated by the binder force [5].

\section{Geometrical Details} $=1.3 \mathrm{~mm}$

Punch diameter: $100 \mathrm{~mm}$, Punch corner radius $=12 \mathrm{~mm}$, Initial Punch temperature $=25$, Thickness

Material Properties: Blank Material $=\mathrm{AZ31B}$, Young's Modulus $=44.8 \mathrm{Gpa}$, Poison's ratio $=0.35$, Friction coefficient $=0.1$, Thermal Properties:, Thermal conductivity $=159 \mathrm{w} / \mathrm{s}^{0} \mathrm{c}$, Heat capacity $=1.7676 \mathrm{w} / \mathrm{mm}^{2}$ c

Thermal conductivity of tool $=60.5 \mathrm{w} / \mathrm{s}{ }^{0} \mathrm{c}$, Heat capacity of tool $=3.41 \mathrm{w} / \mathrm{mm}^{2} \mathrm{c}$, Convection coefficient $=0.03 \mathrm{w} / \mathrm{mm}^{2}{ }^{0} \mathrm{c}$., Interface transfer coefficient $=4.5 \mathrm{w} / \mathrm{mm}^{2}{ }^{0} \mathrm{c}$., Factor to convert plastic deformation energy to heat $=0.95$

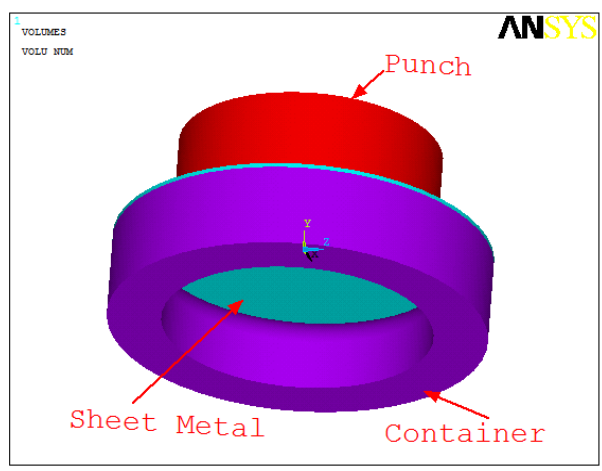

Fig. 2: Geometrical view of the problem

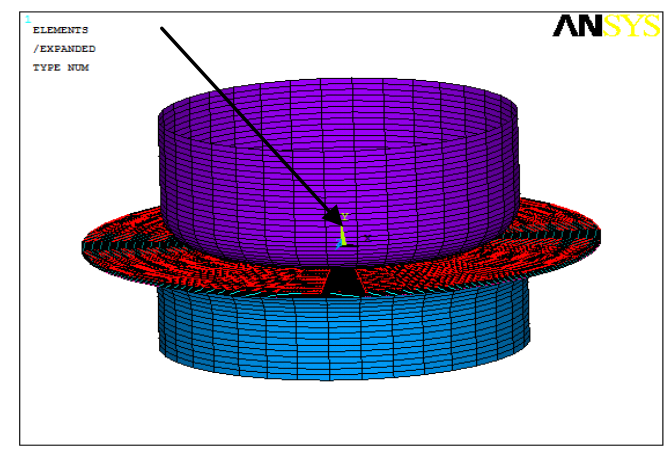

$\left(\mathrm{U}_{\mathrm{X}}=\mathrm{U}_{\mathrm{Y}}=\mathrm{U}_{\mathrm{Z}}=0\right.$, CONSTRAINED)

Fig.4: Meshed plot of the problem

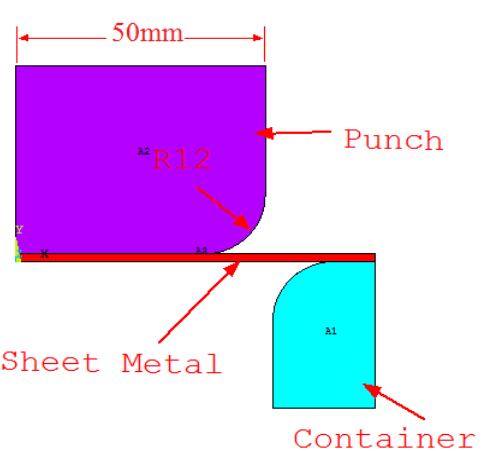

Fig. 3 : Geometrical built up

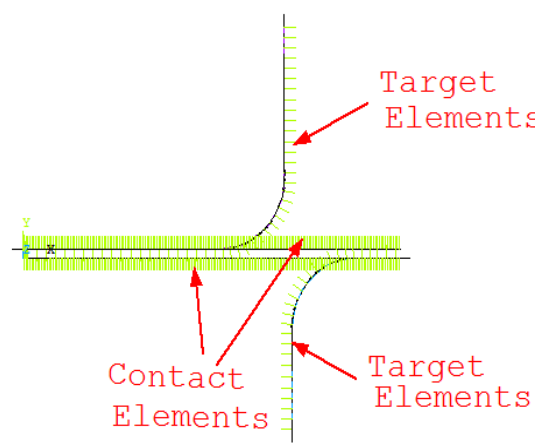

Fig. 5 : Contact definitions

Aassumptions are considered in this research work

- Material is assumed to isotropic and homogenous.

- Analysis is carried out in elasto-plastic domain.

- Analysis is carried out in axisymmetric domain.

- Contact elements are used for analysis whose results depends on iterative solvers which are based on converged values.

- All FEM approximations are applied to anlaysis

- Bi-linearity is assumed for nonlinear stress strain curve.

\section{Results \& Discussion}

The sheet metal formation using deep drawing process is carried out in number of iterations. The formation of sheet metal along with resulting stresses are represented as shown in the following figures. Axisymmetric approach is used to analyse the deep drawing process of sheet metal formation with contact 
elements between punch, sheet metal interface and sheet metal and die interface. Displacement convergence is used to simulate the problem. The total sheet metal process is represented in the figures. The results are analysed for temperature dependent elasto-plastic properties corresponding to $100,150,200$ and $250^{\circ} \mathrm{c}$.

The simulation is carried out with number of steps for better convergence of the problem for deflection, stresses and contact pressure. The results are as follows.

\section{Results Analysis(Case $\left.1-100{ }^{\circ} \mathrm{c}\right)$ :}

Initially the analysis is carried out for temperature dependent properties for $100{ }^{0}$ for hot forming process. Since temperature is low, yield stress is high as shown in the material tables. Similarly due to higher slope of the material curve in the plastic region shows higher resistance for material flow or in-turn increases the stresses. Due to axisymmetric boundary conditions for two dimensional problem, the central left region nodes will not move in the left direction due to the constraint. Even sheet metal right material constrained in all directions to simulate the blank holder position which will not allow free movement of the sheet metal at the end. The stress raise in the plastic region is defined by plastic modulus of the material. Generally higher plastic modulus indicates higher resistance for flow and requires higher punch forces for the movement of the punch. Contac172 element is allowed to move in ux and uy directions with standard lagrangian algorithm with no automated adjustments. Plane182 element has the advantage of simulating the plastic flow with large deformation effect which is not available with earlier elements of Ansys where separate fluid elements need to be defined(visco106) for plastic flow. Now with the higher version the need of visoelements are eliminated and the features are added to 4 noded plane 182 element.

\section{Axisymmetric Simulation results:}

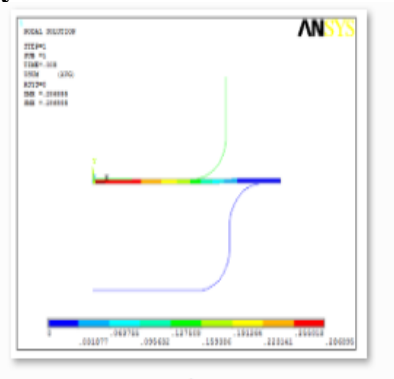

1
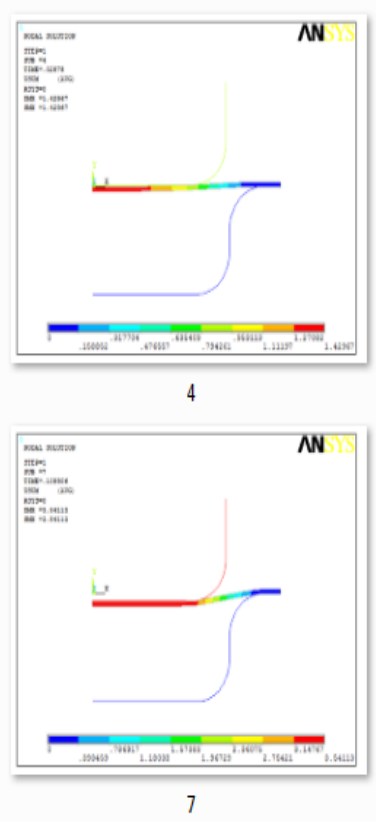

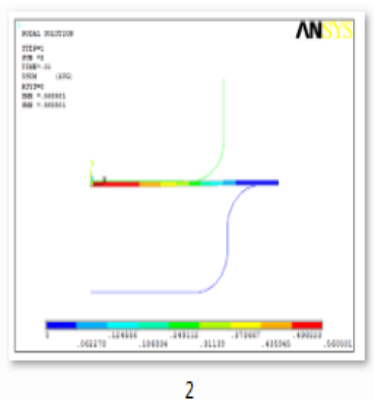

2

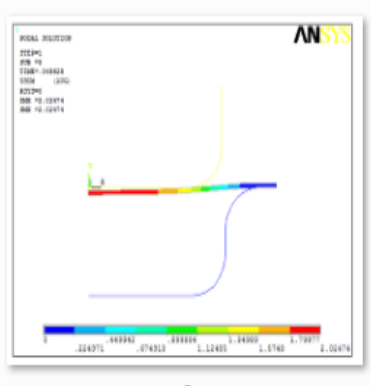

5

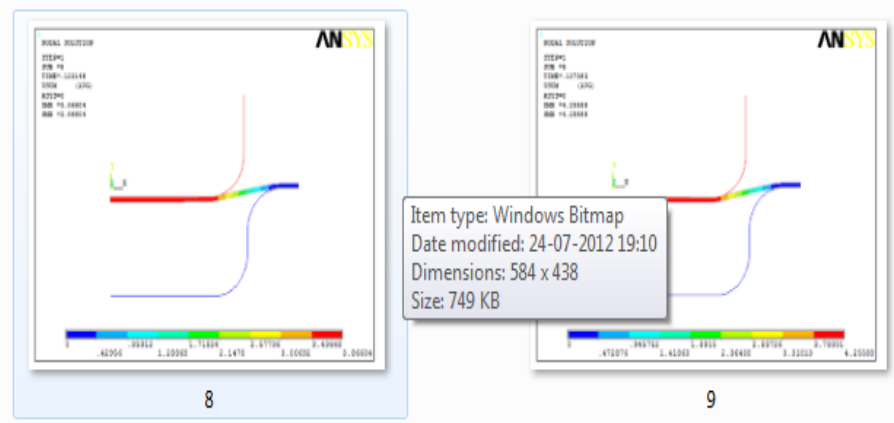

Fig.6: Deformation process (1-15)
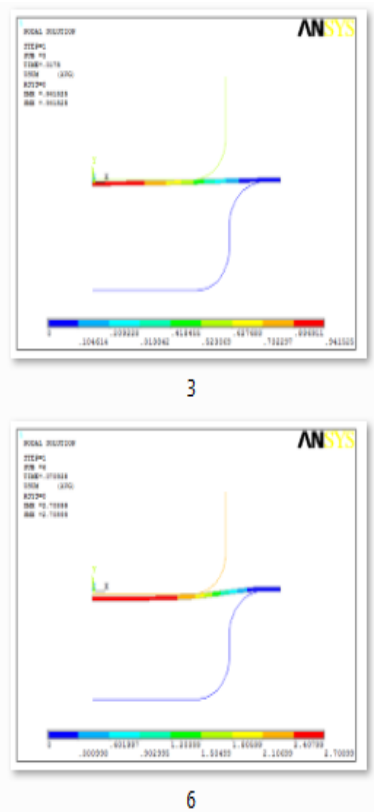

$\mathrm{N}$

\section{.}

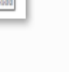




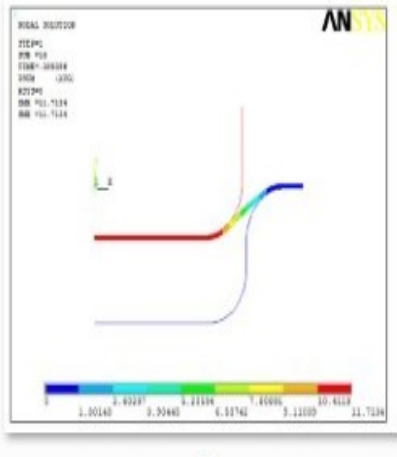

16

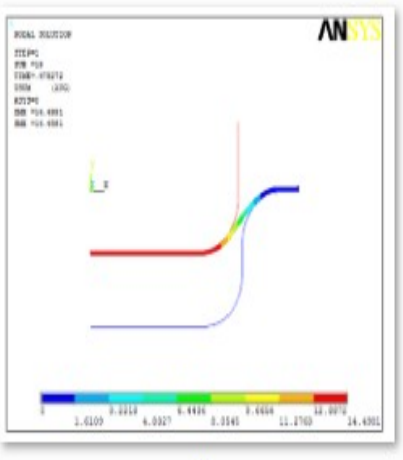

19

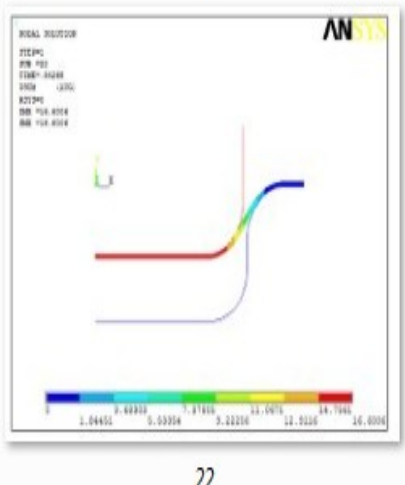

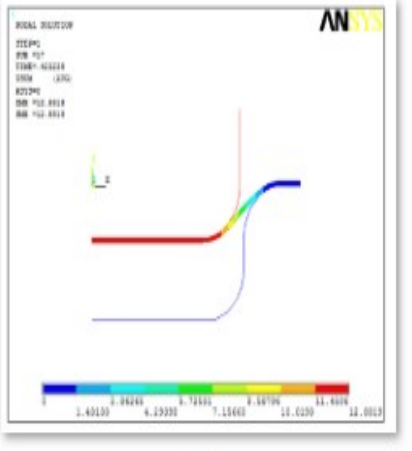

17

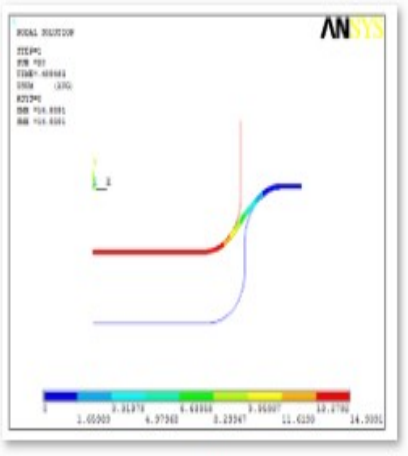

20

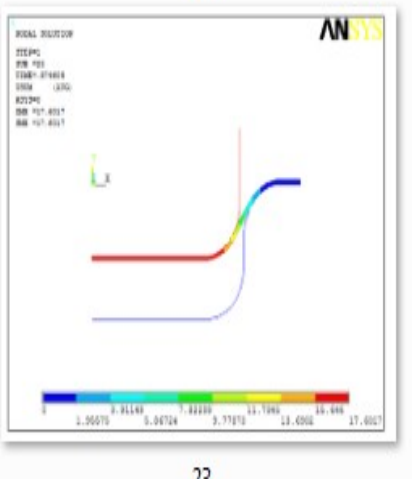

23

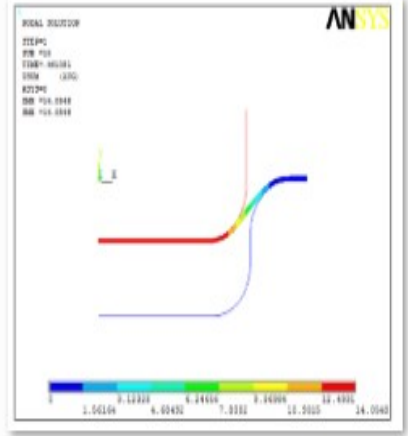

18

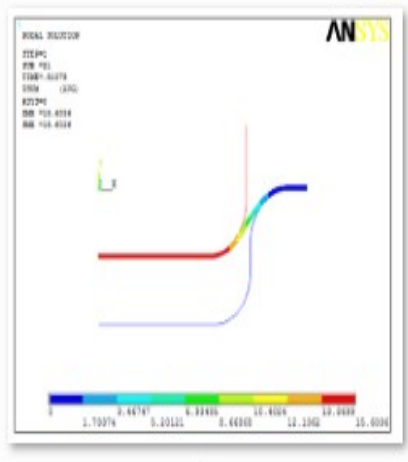

21

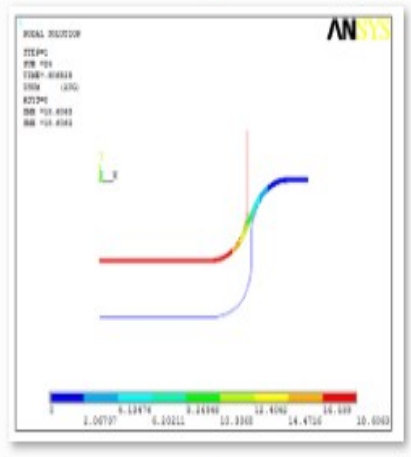

24

Fig.5: Deformation process (16-27) 

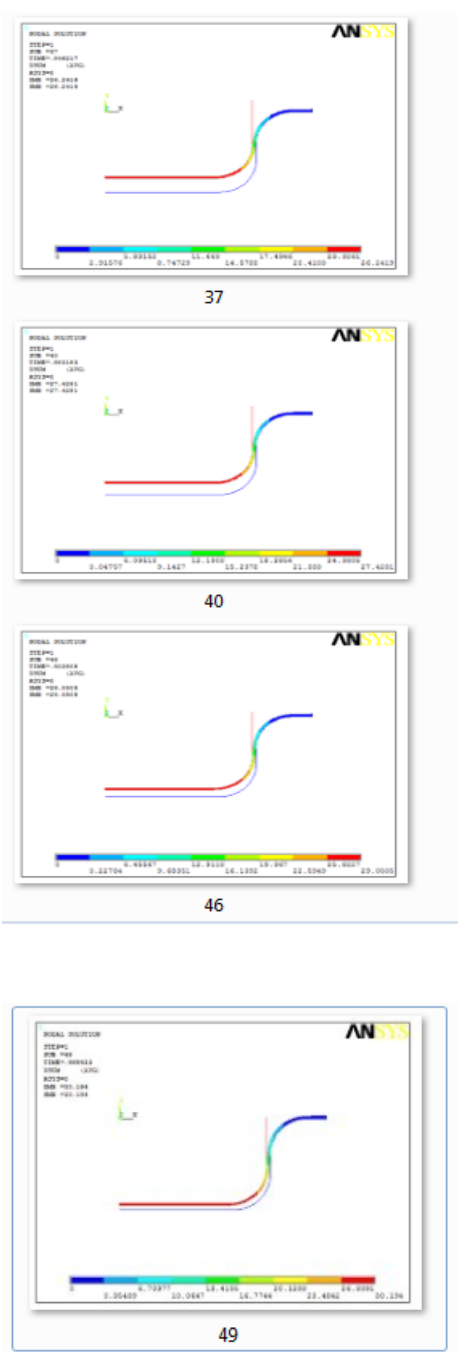
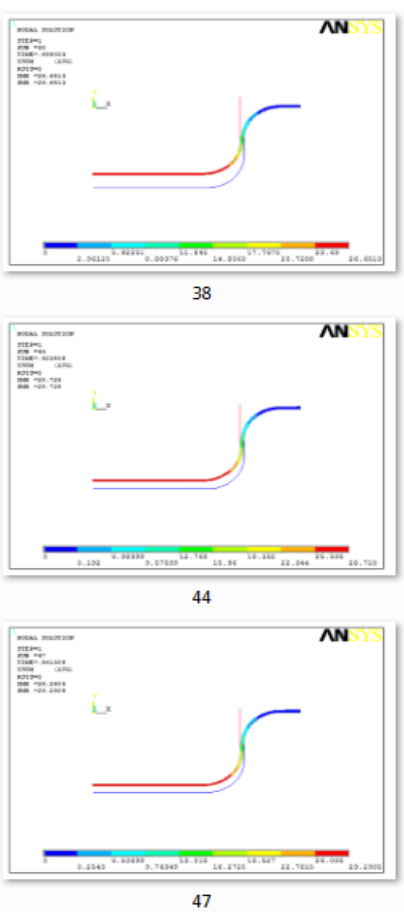
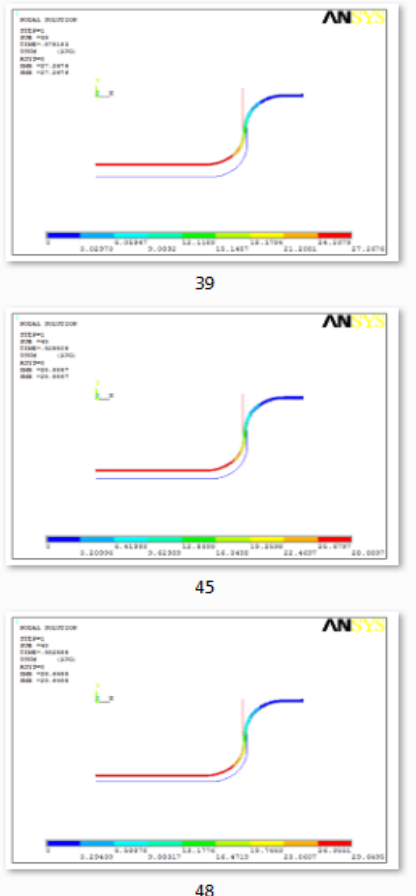

Fig.7: Deformation process (27-48)
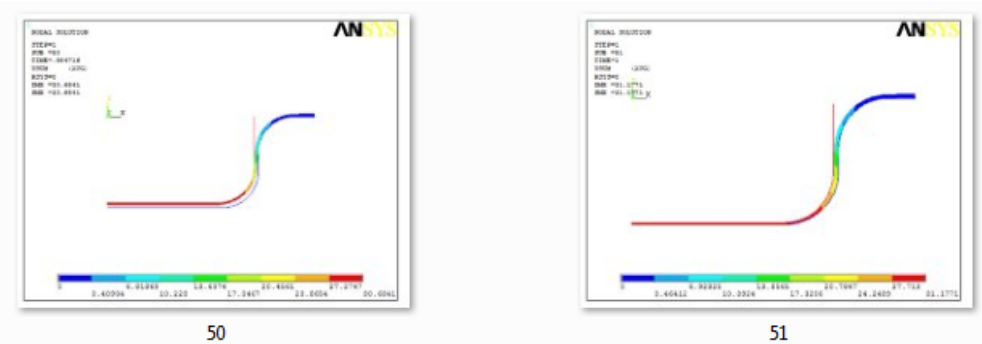

Fig.8: Deformation process (49-51)

The figures 6 to 8 shows slow deformation process of sheet metal with the punch movement. A total of 51 steps are required for converged results to get $31 \mathrm{~mm}$ displacement. Final picture shows complete converged results sitting between punch and die interface. Maximum deformations are observed at the left bottom and minimum deformation to the right end. The sheet metal is following the curvature given for both punch and the die.

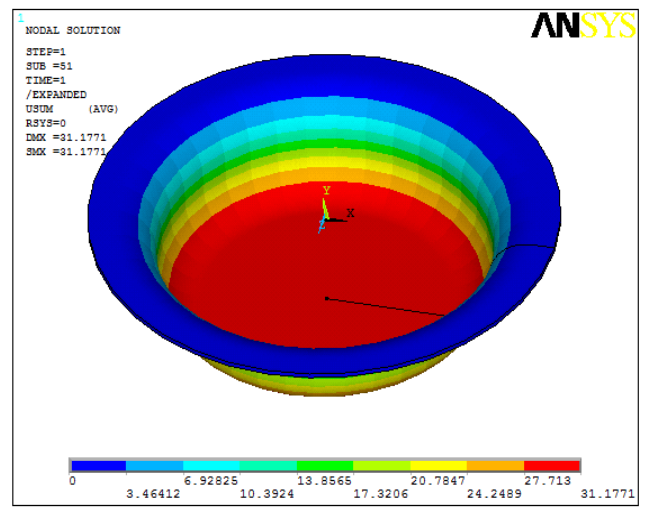

Fig.9: Expanded displacement plot

The figure 9 shows deformation of $31.171 \mathrm{~mm}$ due to punch movement. Maximum deformation is observed at the bottom and minimum deflections at the top. The status bar at the base shows variation of displacements. A gradual change of deformation can be observed. The displacement convergence used in the 
problem helps in obtaining the deformation in the sheet metal. Totally 51 iterations are carried out to obtain the required deformation of $31 \mathrm{~mm}$. In each step, a small incremental displacement is applied on the sheet metal.

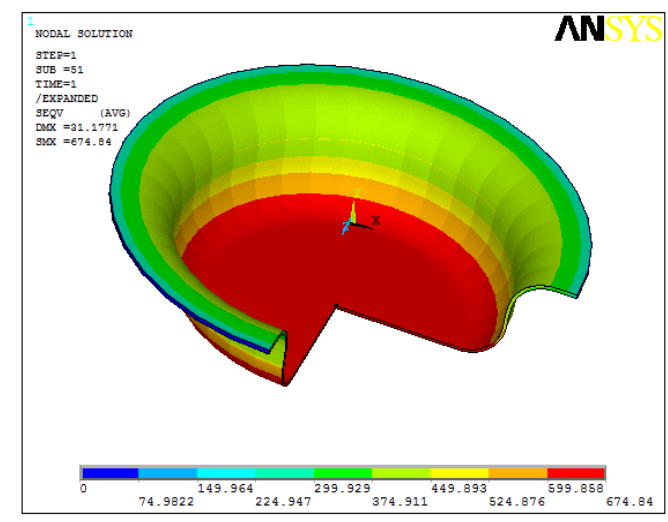

Fig.10: Vonmises Stress plot

The figure 10 shows the developed stress in the deep drawing process. Maximum vonmises stress of $674.84 \mathrm{Mpa}$ can be observed at the end of sheet metal formation. The red color region shows maximum stress region. The blue color region shows minimum stresses in the structure. The bottom of the sheet metal is plastically yielding due to which it showing stress higher then the yield stress of the material.

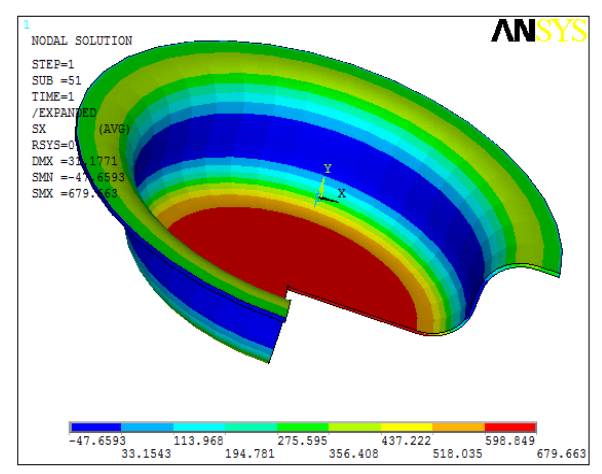

Fig.11: Radial Stress Plot

The figure 11 shows radial stress generation in the deep drawing process. Maximum stress is on the tension side. Radial stress helps in finding the compressive and tensile stresses in the problem. Maximum compressive stress is around $47.2593 \mathrm{~N} / \mathrm{mm}^{2}$ and a tensile stress of $679.663 \mathrm{Mpa}$ can be observed in the problem. From the observation, maximum radial compressive stress is taking place as shown by blue colour region. Radial tensile stress is observed at the base of the structure.

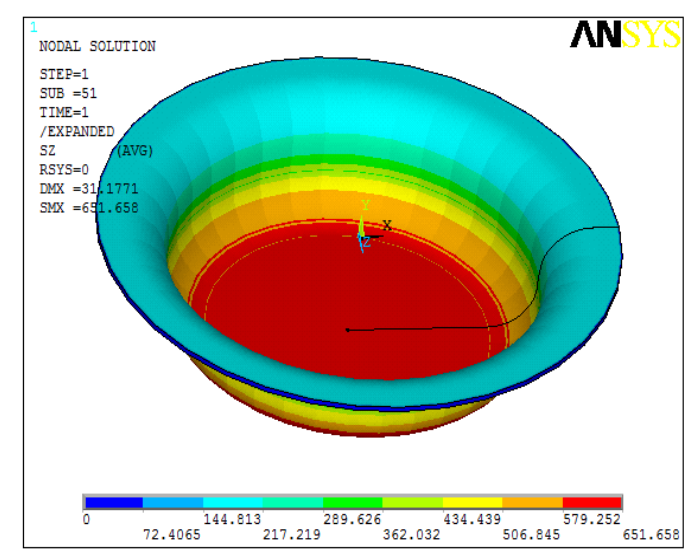

Fig.12: Hoop Stres Plot 
The figure 12 shows hoop stress distribution in the member. Maximum hoop stress is around $651.658 \mathrm{Mpa}$ in tension. Generally hoop stress is the main failure stress in the axisymmetric problems. Maximum hoop stress is also observed at the base of the sheet metal as shown by red colour. The status bar at the bottom shows variation in the stress pattern.

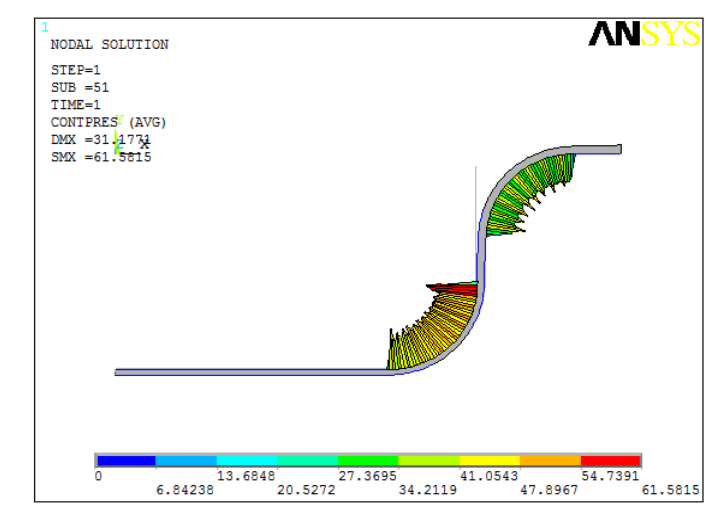

Fig.13: Contact Pressure Plot

The figure 13 shows contact pressure development in the problem. Maximum contact pressure is around $61.5815 \mathrm{Mpa}$ as shown at the curved region. Maximum contact pressures are taking place at the curved regions. Contact pressure is observed more at the bottom curvature compared to the top geometry.

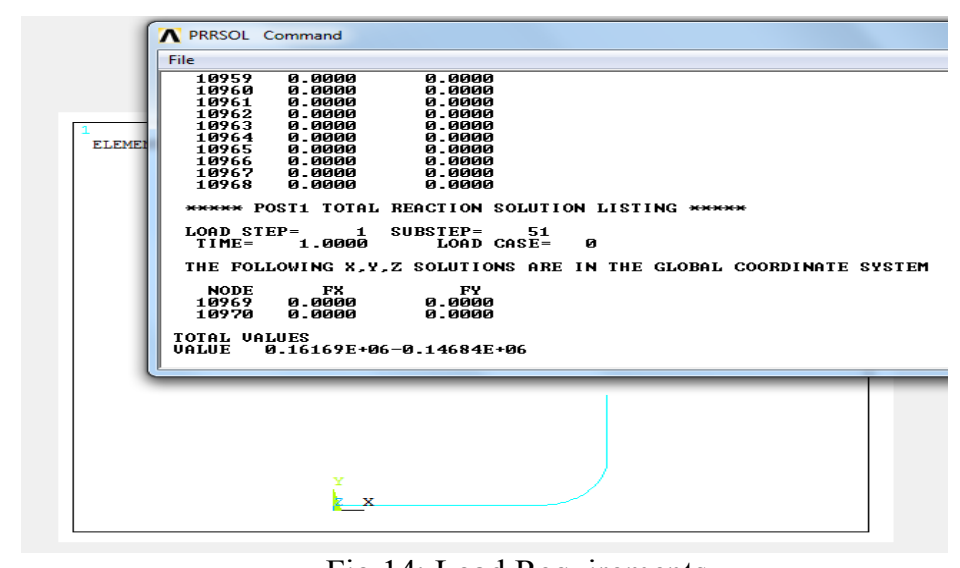

Fig.14: Load Requirements

The figure 14 shows load requirement of the problem. The load results are obtained by listing reaction solution on nodes corresponding to punch target elements. The load is represented in both the axis. So the resultant load can be obtained mathematically as

$\mathrm{Fr}=\operatorname{sqrt}\left(\mathrm{Fx}^{2}+\mathrm{Fy}^{2}\right)$

$\mathrm{Fr}=\operatorname{sqrt}\left(161690^{2}+(-146840)^{2}\right)=\sim 218416 \mathrm{~N}$

So the above load is required for $31 \mathrm{~mm}$ depth sheet metal formation. Thus Finite element softwares helps in estimating the punch loads required without prototype being tested. Similarly analysis is continued with increased deep drawing process corresponding to 35,40 and $45 \mathrm{~mm}$ to analyse the load requirements for the drawing process. 


\section{Similarly case 2}

\section{Results for Case 2 (Deep Drawing of 35mm)}
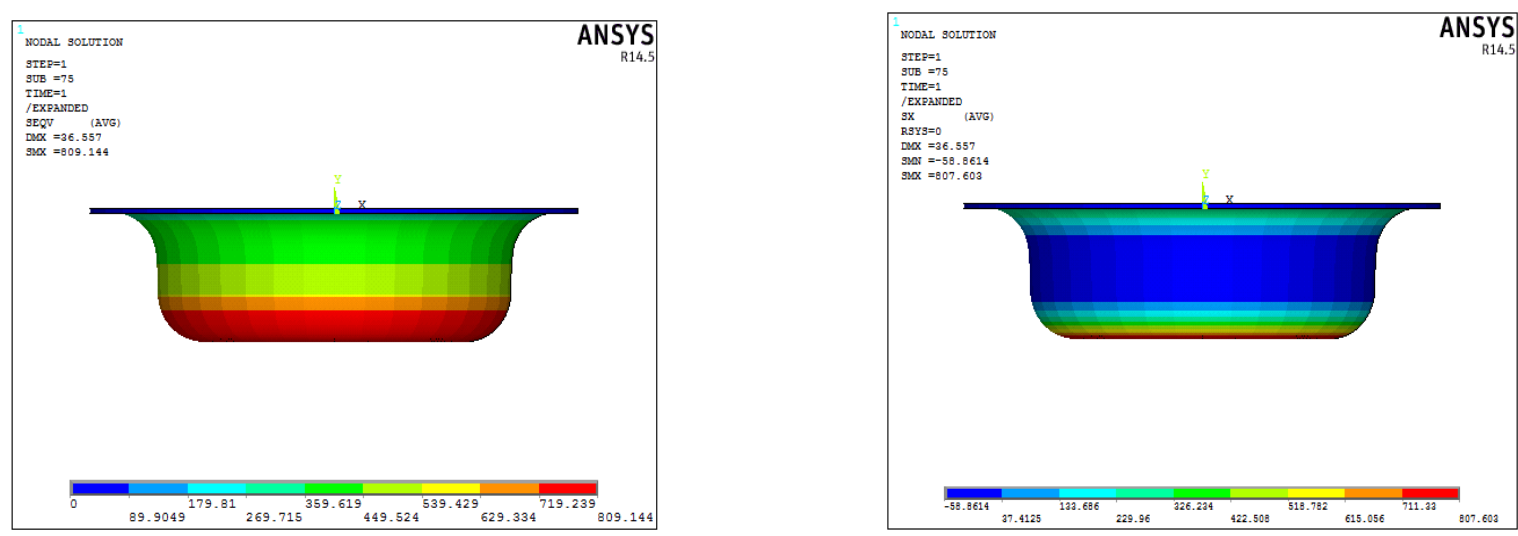

Fig. 15: Vonmises Stress Plot

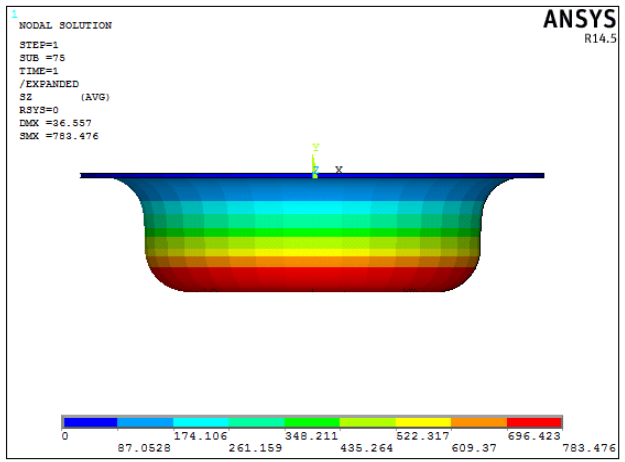

Fig. 17: Hoop Stress Plot

Fig.16: Radial Stress Plot

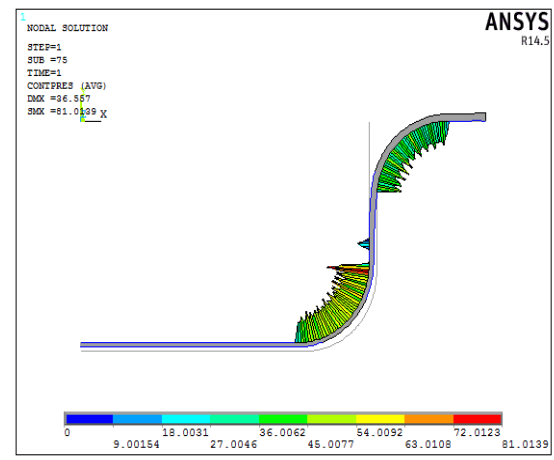

Fig. 18: Contact Pressure Plot

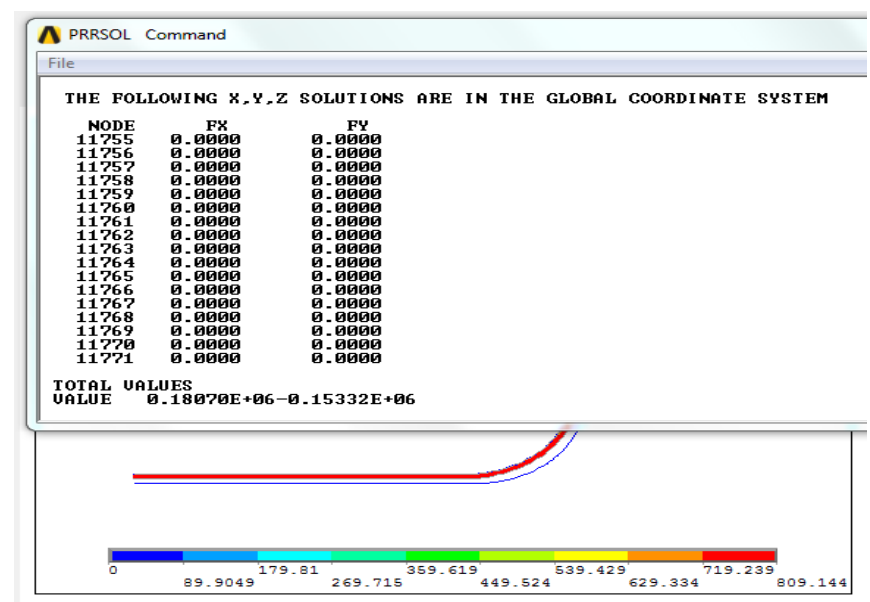

Fig.19: Load Requirements

The figure 19 shows load requirement of the problem for $35 \mathrm{~mm}$ deep drawing process. The load results are obtained by listing reaction solution on nodes corresponding to punch target elements. The load is represented in both the axis. So the resultant load can be obtained mathematically as $\mathrm{Fr}=\operatorname{sqrt}\left(\mathrm{Fx}^{2}+\mathrm{Fy}^{2}\right)$ $\mathrm{Fr}=\operatorname{sqrt}\left(180700^{2}+(-153320)^{2}\right)=\sim 236979 \mathrm{~N}$

So a load of $236979 \mathrm{~N}$ is required for $35 \mathrm{~mm}$ depth sheet metal formation. So a increase of punch load from $218416 \mathrm{~N}$ to $236979 \mathrm{~N}$ can be observed with increased depth of deep drawing process. So 8.5\% load increment can be observed for the process. 


\section{Results for Case 3 (Deep Drawing for 40mm):}

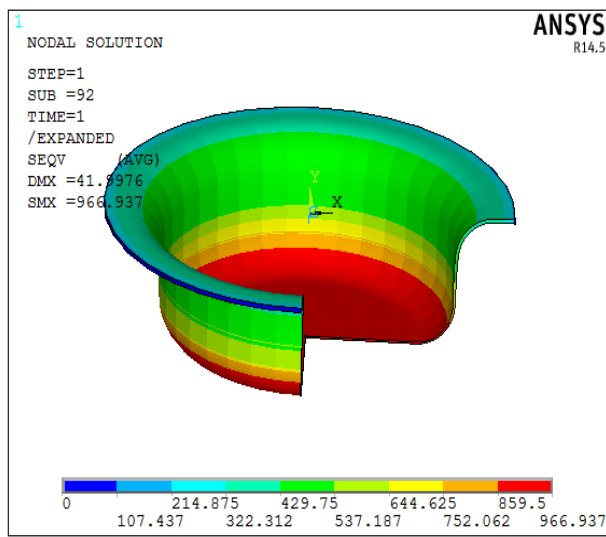

Fig.20: Vonmises Stress plot

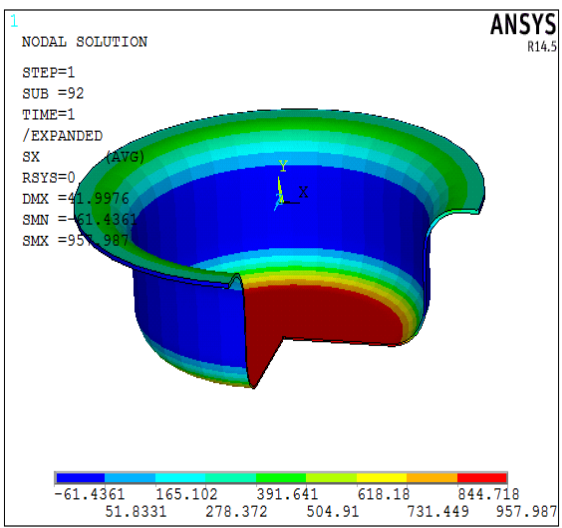

Fig.21 : Radial Stress Plot

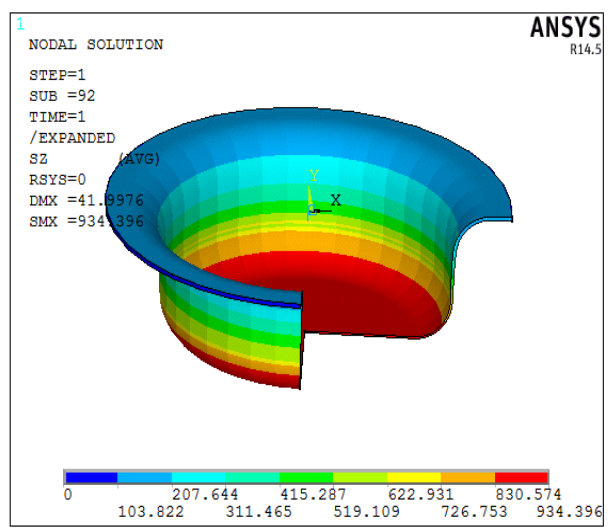

Fig.22: Hoop Stress Plot

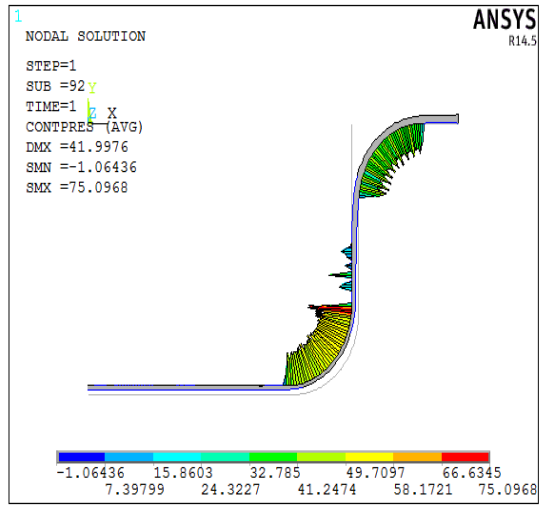

Fig.23: Contact Pressure Plot

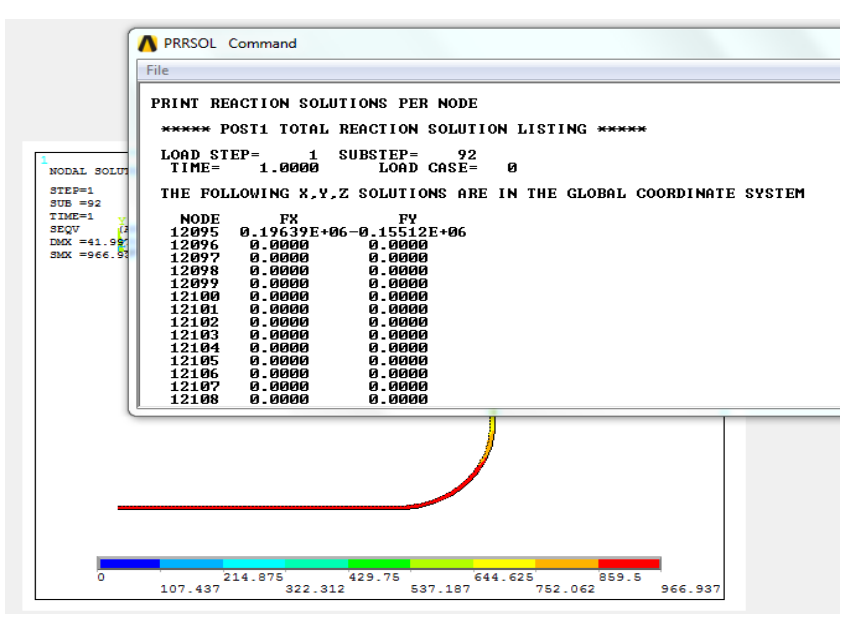

Fig.26: Load Requirements

The figure 26 shows load requirement of the problem $40 \mathrm{~mm}$ deep drawing process. The resultant load can be obtained mathematically as

$\mathrm{Fr}=\operatorname{sqrt}\left(\mathrm{Fx}^{2}+\mathrm{Fy}^{2}\right)$

$\mathrm{Fr}=\operatorname{sqrt}\left(196390^{2}+(-155120)^{2}\right)=\sim 250262 \mathrm{~N}$

So a load of $250262 \mathrm{~N}$ is required for $40 \mathrm{~mm}$ depth sheet metal formation. So an increase of punch load from $218416 \mathrm{~N}$ of initial load to $250262 \mathrm{~N}$ can be observed with increased depth of drawing process. (So an increase of $14.5 \%$ of load can be observed). 
Analysis Results for Case $4 \mathbf{- 4 5}$ depth of deep drawing process:

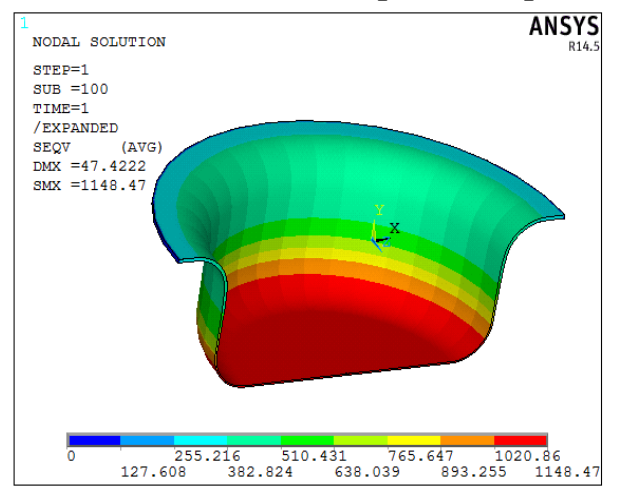

Fig.27: Vonmises Stress Plot

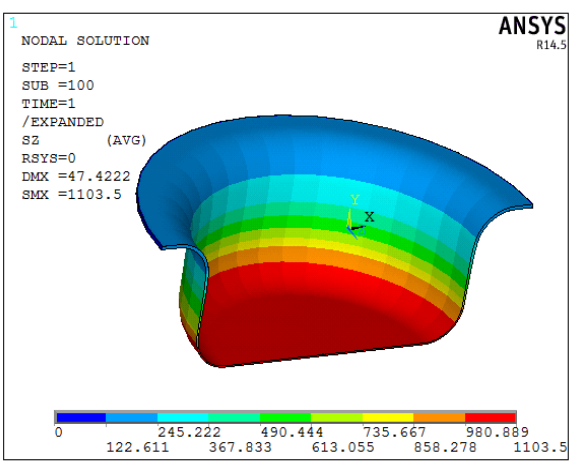

Fig.29: Hoop Stress Plot

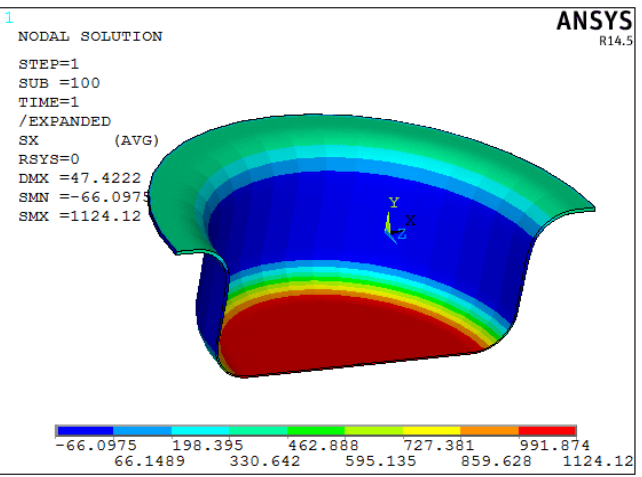

Fig.28: Radial Stress Plot

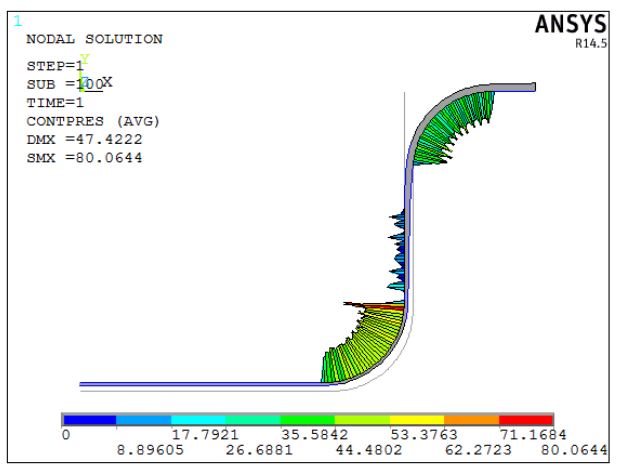

Fig.30: Contact Pressure Plot

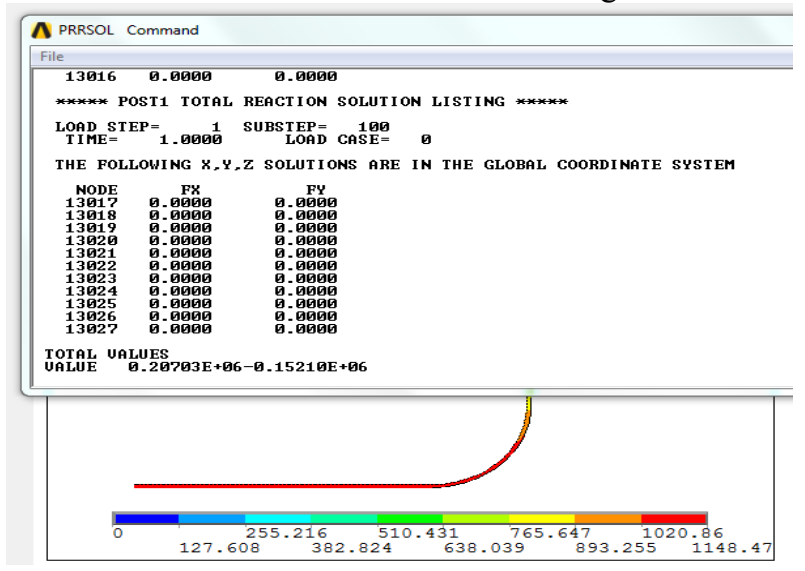

Fig.33: Load Requirements

The figure 33 shows load requirement of the problem for $45 \mathrm{~mm}$ forming process. Here also the load is resolved in two two mutually perpendicular axis based on the degree of freedom used in the problem. Mathematically the resultant load can be obtained as

$\mathrm{Fr}=\operatorname{sqrt}\left(\mathrm{Fx}^{2}+\mathrm{Fy}^{2}\right)$

$\mathrm{Fr}=\operatorname{sqrt}\left(207030^{2}+(-152100)^{2}\right)=\sim 256896 \mathrm{~N}$

So a load of $256896 \mathrm{~N}$ is required for $45 \mathrm{~mm}$ depth sheet metal formation. So a reduction of punch load from $218416 \mathrm{~N}$ of initial load to $256896 \mathrm{~N}$ can be observed with increased deep drawing loads(So an increase of $15 \%$ of load can be observed).

Table 1: Load requirements

\begin{tabular}{|l|l|l|l|l|l|}
\hline Deep Drawing & Vonmises & Radial Stress & Hoop Stress & $\begin{array}{l}\text { Contact } \\
\text { Pressure }\end{array}$ & Load Requiements(KN) \\
\hline 30 & 674 & 679 & 651 & 61 & 218.416 \\
\hline 35 & 809 & 807 & 783 & 81 & 236.979 \\
\hline 40 & 966 & 957 & 934 & 75 & 250.262 \\
\hline 45 & 1148 & 1124 & 1103 & 80 & 256.896 \\
\hline
\end{tabular}


Table 2: Load and stress generation with reference to the fillet radius

\begin{tabular}{|l|l|l|l|l|l|}
\hline $\begin{array}{l}\text { Fillet Radius } \\
(\mathrm{mm})\end{array}$ & Vonmises & Radial stress & Hoop Stress & Contact Pressure & $\begin{array}{l}\text { Load } \\
(\mathrm{kN})\end{array}$ \\
\hline 6 & 870 & 560 & 812 & 123 & 242.412 \\
\hline 8 & 795 & 794 & 756 & 109 & 235.573 \\
\hline 10 & 731 & 736 & 701 & 87 & 227.446 \\
\hline 12 & 674 & 679 & 651 & 61 & 218.416 \\
\hline
\end{tabular}

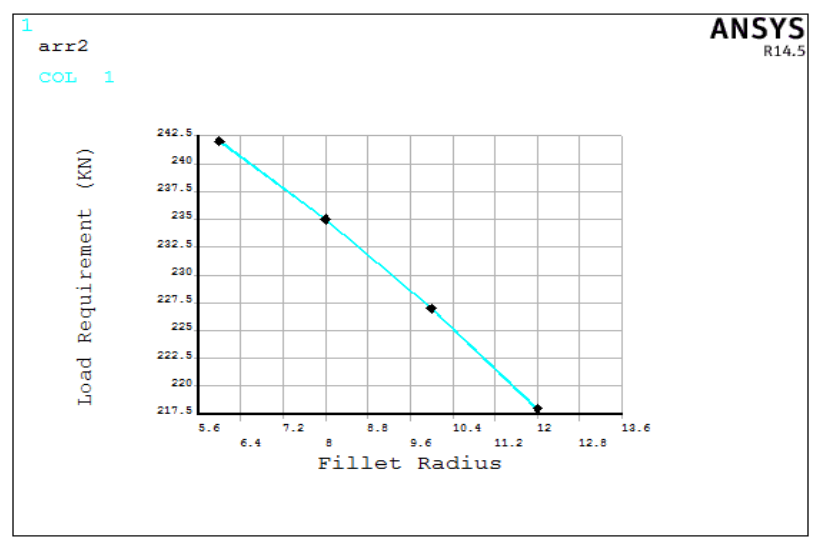

Fig.34: Fillet Vs Punch Load

\section{Conclusion}

Sheet metal formation during deep drawing process is simulated using Finite element software and analysis is carried out to find the load requirements with increase deep drawing forming process. The results summary is as follows.

Initially the punch, sheet and fixed die are modeled as per the specifications. Later the structure is meshed with 4 noded quad elements(Plane182). The element is capable of representing the large deflection effect with plastic capabilities. Contact pairs are created between punch, sheet metal interface, die, sheet metal interface using Targe 169 and Contac172 elements. The displacement load is applied and problem is executed in the nonlinear domain using material properties specified for given temperature range.

- Analysis has been carried out for load requirements for sheet metal formation. The results shows increased load requirements with increased depth of drawing process. The stress values for radial, hoop, vonmises and contact pressure are increasing. From the finite element simulation, the region of thinning and probable regions of failure can be identified. Higher stress regions are the major regions of failures. Finite element simulation helps in avoiding prototype built up and checking for the required load calculations.

- The results shows punch load requirement of $218.416 \mathrm{KN}$ at $30 \mathrm{~mm}$ to $256 \mathrm{KN}$ load for $45 \mathrm{~mm}$ deep drawing proces. So depth drawing process increases the load requirements.

- Further analysis is carried out to find the effect of fillet radius on the punch load and stress generation. The results shows increased value of fillet reduces the punch load requirement along with the reduction of stresses. The fillet variation of $6 \mathrm{~mm}$ to $12 \mathrm{~mm}$ shows shows reduction of $242.412 \mathrm{KN}$ of punch load to 218. $416 \mathrm{KN}$ (Almost $10 \%$ reduction of punch load). Similarly stresses are reducing to the greater extent. So punch radius plays significant role on punch load requirements.

\section{References}

[1]. Klaus-Jurgen Bathe, On the State of Finite Element Procedures for Forming Processes, (C) American institute of physics, 0-73540188-8/04/, CP712 MATERIAL PROCESSING AND DESIGN.

[2]. Hakim S. Sultan Aljibori," : "Finite element Analysis of Sheet Metal Forming Process", European Journal of Scientific Research, ISSN 1450-216X Vol.33 No.1 (2009), pp.57-69.

[3] Y. Park, J. S. Colton, "Failure Analysis Of Rapid Prototyped Tooling In Sheet Metal Forming-V-Die Bending", Journal Of Manufacturing Science And Engineering, February 2005, Vol. 127

[4]. Otto Harrer "Finite element simulation in metal forming" Acta Montanistica Slovaca Ročník 8 (2003), p 176.

[5]. SRIPATI SAH, “Investigation Of Contact Pressure Distribution On Sheet Metal Stamping Tooling Interfaces: Surface Modeling, Simulations, And Experiments", University of Massachusetts, 2007. 